\title{
PETROLOGIA DAS LAVAS ULTRABÁSICAS E BÁSICAS DA SEQUUENNCIA VULCANO-SEDIMENTAR MORRO DO FERRO. FORTALEZA DE MINAS (MG)
}

\author{
NOEVALDO ARAUJO TEIXEIRA* e JOSÉ \\ CARUSO MORESCO DANNI**
}

\begin{abstract}
In this work the petrology of the Archean Morro do Ferro volcano-sedimentary sequence is being defined. The sequence is located in southwest part of the São Francisco Craton in the vicinity of the Fortaleza de Minas Village. The basal part of the Greenstone belt of Morro do Ferro is constituted of ultramafic flows with spinifex texture intercalated with aluminous tuffs, and iron formation. The medium part is formed of massive basaltic flows, now represented by tremolite-chlorite-epidote schist associa ted with reworked volcanic rocks, iron formation and talc schist lenses. The petrological studies indicated a fractionation trend wich starts with rocks of komatiitic afiliation (peridotite, pyroxenite, basalt) to rocks of tholeiitic composition (basalt). The fractionation is caracterized by a decrease in $\mathrm{MgO}$ content, a constant $\mathrm{CaO} / \mathrm{Al}_{2} \mathrm{O}_{3}$ ration, that reflects the olivine crystalization in the initial stages, followed by clinopiroxene and plagioclase.
\end{abstract}

INTRODUÇÃO Pretende-se traçar a evolução petrológica da seqüência vulcano-sedimentar Morro do Ferro, enquadrando suas rochas dentro dos grupos magmáticos já conhecidos e em seguida, com base em parâmetros das rochas vulcânicas, comparar com as suites arqueanas do Canadá, África do Sul e Austrália. As frações félsicas do vulcanismo não foram analisadas em razão da inexistência de amostras satisfatórias, o que não permitiu a completa caracterização do "trend" de diferenciação. Por isso, não há nos diagramas de IS, AFM, etc. curvas completas.

As litologias analisadas sofreram pelo menos três etapas de deformações distintas, que foram acompanhadas por dois períodos de recristalizações metamórficas. Assim, as interpretações petrológicas devem ser consideradas com cautela, principalmente com respeito às variações de $\mathrm{Na}_{2} \mathrm{O}$ e $\mathrm{K}_{2} \mathrm{O}$, pois há possibilidade de que o sistema envolvido não tenha se comportado isoquimicamente. Outro fator prejudicial para uma correta interpretação do estudo é a acentuada alteração intempérica das rochas da seqüência. Em superficie é praticamente impossivel uma amostragem sistemática.

CARACTERIZAÇÃO GEOLÓGICA A seqüência vulcano-sedimentar Morro do Ferro, localiza-se na porção sudoeste do Estado de Minas Gerais, a oeste das cidades de Itaú e Fortaleza de Minas, distando $360 \mathrm{~km}$ de Belo Horizonte pela MG-056. É constituída na base por derrames de lavas ultrabásicas, possuindo localmente textura spinifex fina, caracte- rística de topo dos derrames descritos por Arndt et al. (1977), no Abitibi belt, intercalações regulares de precipitados químicos como chert, chert ferrífero, rochas dedríticas, níveis tufogênicos e vulcânicas ácidas retrabalhadas. A porção média compreende lavas básicas, lentes de rochas ultrabásicas, ritmitos e chert ferrífero. $O$ topo é constituído por um espesso pacote sedimentar representado por filitos localmente grafitosos e chert ferrífero (Fig. 1).

Tal sequiência apresenta metamorfismo do fácie xisto verde, estando embutida no embasamento siálico constituído por ortognaisses leucocráticos, migmatitos, zonas lineares de rochas cataclásticas e corpos graníticos, componentes da porção côncava meridional do Craton São Francisco. A análise da estratigrafia, intensidade do metamorfismo, tipos litológicos, texturas vulcânicas preservadas e posicionamento indicam que tal unidade corresponde a "raiz" de um greenstone belt (Teixeira e Danni, no prelo). A porção estudada possui $30 \mathrm{~km}$ de extensão por $3 \mathrm{~km}$ de largura, com espessura máxima de $700 \mathrm{~m}$. Schmidt e Fleischer (1978), indicam que tais rochas se estendem por mais de $100 \mathrm{~km}$, no sentido sudeste.

ANÁLISES QUÍMICAS A Tab. 1 contém as análises e suas respectivas normas. $O$ estado de oxidação primitivo não foi corrigido, pois a premissa de um conteúdo de $\mathrm{Fe}_{2} \mathrm{O}_{3}$ - padrão poderia mascarar uma nova filiação magmática. Conclui-se que as primitivas rochas ultramáficas teriam como máficos principais o diopsídio, hiperstênio, olivina e magnetita, atual-

* Metais de Goiás S/A - METACO - Rua 68 N. ${ }^{\circ} 727$ - Goiânia (GO)

** Depto. de Geociencias - Universidade de Brasília - Brasília (DF) 
COLUNA LIITOESTRATIGRÁFICA COMPLETA DO CINTURÄO VULCANO-SEDIMENTAR

MORRO DO FERRO
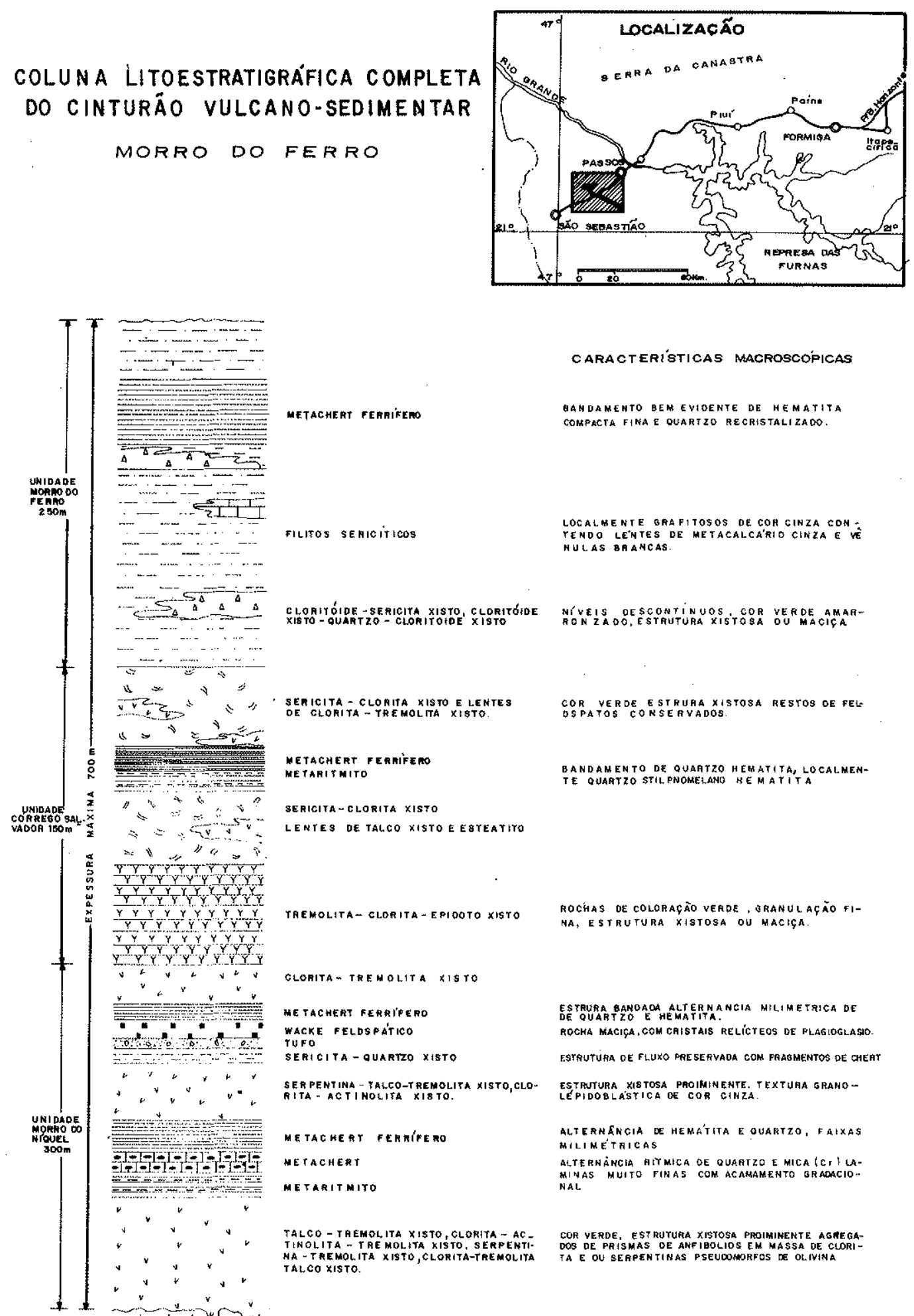

METACHERT FERAIKEMO COMPACTA FINAE QVARTZO RECRISTALIZADO.

LOCALDENTE GRAFITOSOS DE COR CINZA CON

FILITOS SERIC ITICOS NULAS BAANCAS.

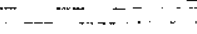

(2)

$-5_{4} S_{4}=$

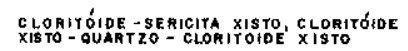

NIVEIS OESCONTINUOS COR VERDE AMAA-
FONZADOE ESTGUTURA XISTOSA OU MACIGA

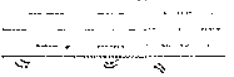

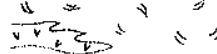

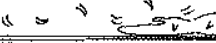

SERICITA- CLORITA XISTO ELENTES
OE CLORITA-TREMOLTA XISTO.

METACHERT TERMIFE

METAFITMITO

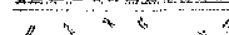

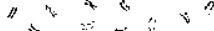

SERICITA- GLoRITA XISTO

LENTES DE TALCO XISTOE ESTEaTiro

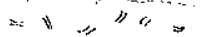

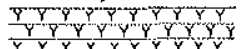

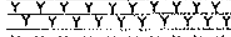

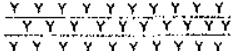

TAEMOLITA- CLORITA-EPIDOTO XISTO

Rochas oE coloraģ̃o verde, orranul açĩo fiHA, ESTRUTURA XISTOSA OU MACIGA

CLORITA - TREMOLITA XISTO

METACHERT FERRITERO

MACKE FELDSPÁtico

SERicita - QUARTZO Xisto

SERPENTINA-YALCOO-TREMOLITA XISTO, CLO-
BITA. ACTINOLIYA XI8TO.

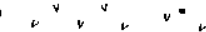

METACHE RT FERTIFE nO

NETACHERT

METARIT MIYO

TALCO - TAEMOLLTA XISTO, CLORITA - ACTENOOLTAA- YRE MOLITA XISTOO SERPEETNA TRE MOL ITA
TALCO XISTO.

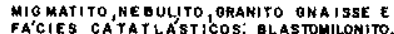
FA'CIES CATATLASTTCOS: BLASTMMILONTEO DILUES DE TRE MOLITA- GLOAHITA XISTO

ROCHAS LEUCOCAA'TICAS SEM SEPARAÇO VISIVEL DO PALEOSSOMA E NEOSSOMA, AGREGADOS DE BHOTITA CONTORCAOOS $\varepsilon$ ESTRUTURAS MACLCAS. CATACLASTICAS. AUG ENS, ES -
THUTURA DE FLUXXO CATACLASTICOS. MOAGEM INTENSA QUARTZO AIBGOH.

ESTRURA GANOAOA ALTERNANCIA MLLIMETTICA DE
DE QUARTZO E HEMATITA. ROCHA Maciga, COM CAISTAIS RELícteos de plagioglasio.

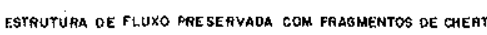
ESTRUTURA XISTOSA PAOIMINENTE. TEXTUAA GRANO-
LÉPIDOBLASYICA OE COR CINZA.

ALTERHENGIA DE HEMÁTITA E OUARTZO, FaiKas MILIMETTRICAS

ALTERNÁNCIA AITMLCA DE QUAATZO E MICA LCI $T$ CAMINAS MUITO FINAS COM ACAMAMENTO GRADACIO-

COR VERDE, EST RUTUAA XISTOSA PROIMINENTE AGMEGGADOS DE PA IS MAS OE ANF IEOLIOS EM MASSA OE CLORI 
mente transformados em paragêneses metamórficas, constituídas sobretudo por tremolita-actinolita e clorita. A destruição do plagioclásio cálcico originou epidoto, calcita e albita. O titânio liberado dos piroxênios, cristalizou como titanita e ilmenita. Os serpentinitos são apreciavelmente ricos em $\mathrm{MgO}$, pobres em $\mathrm{SiO}_{2}, \mathrm{TiO}_{2}, \mathrm{CaO}$ e $\mathrm{Na}_{2} \mathrm{O}$.

Chama a atenção, o fato de que os xistos ultramáficos possuem significantes quantidades de ensta- tita e plagioclásio normativos, embora estes minerais não sejam constatados em lâmina. Tal fato também ocorre nos flows ultrabásicos de Munro como mostra Pyke et al (1973). A explicação sugerida pelo autor envolve a cristalização primária de piroxênio rico em alumínio. No cálculo da norma parte do cálcio do piroxênio é convertido em moléculas de anortita, possibilitando em conseqüência a conversão de parte do diopsídio em enstatita.

Tabela 1 - Análises químicas e normas

\begin{tabular}{|c|c|c|c|c|c|c|c|c|c|c|c|c|c|c|c|c|}
\hline & \multicolumn{2}{|r|}{1} & \multicolumn{2}{|r|}{2} & \multicolumn{2}{|c|}{3} & \multicolumn{2}{|c|}{4} & \multicolumn{2}{|c|}{5} & \multicolumn{2}{|c|}{6} & \multicolumn{2}{|c|}{7} & \multicolumn{2}{|l|}{8} \\
\hline$U_{2}$ & 45.50 & $(49.78)$ & 49.00 & $(51.02)$ & 43.20 & $(45.85)$ & 45.40 & $(47.30)$ & 47.90 & $(48.99)$ & 45.50 & $(48.41)$ & 48.50 & $(49.81)$ & 48.30 & $(50.63)$ \\
\hline 2 & 2.80 & $(3.06)$ & 9.40 & $(9.78)$ & 2.90 & (3.07) & 5.70 & $(5.93)$ & 4.80 & $(4.90)$ & 9.20 & $(9.79)$ & 13.40 & (13.76) & 16.70 & $(17.50)$ \\
\hline $\mathrm{Fe}_{2} \mathrm{O}_{3}$ & 7.50 & $(8.20)$ & 0.93 & $(0.96)$ & 3.99 & (4.23) & 4.10 & $(4.27)$ & 3.45 & (3.52) & 4.50 & $(4.78)$ & 3.82 & $(3.92)$ & 4.40 & $(4.61)$ \\
\hline $\mathrm{FeO}$ & 4.60 & (5.03) & 8.70 & $(9.05)$ & 8.07 & (8.56) & 9.99 & $(10.40)$ & 9.13 & $(9.33)$ & 6.50 & $(6.91)$ & 7.99 & $(8.20)$ & 6.50 & $(6.81)$ \\
\hline $\mathrm{MnO}$ & 0.00 & $(0.00)$ & 0.17 & $(0.17)$ & 0.17 & $(0.18)$ & 0.23 & $(0,23)$ & 0.22 & $(0.22)$ & 0.00 & $(0.0)$ & 0.18 & $(0.18)$ & 0.00 & $(0.00)$ \\
\hline $\mathrm{MgO}$ & 27.30 & $(29.87)$ & 17.20 & $(17.90)$ & 27.10 & $(28.76)$ & 18.20 & $(18.96)$ & 18.40 & (18.81) & 17.50 & (18.62) & 11.50 & (11.81) & 5.40 & $(5.66)$ \\
\hline $\mathrm{CaO}$ & 3.20 & (3.50) & 9.00 & $(9.37)$ & 7.10 & (7.53) & 10.40 & $(10.83)$ & 11.80 & $(12.06)$ & 9.90 & (10.53) & 7.70 & $(7.90)$ & 9.20 & $(9.64)$ \\
\hline $\mathrm{Na}_{2} \mathrm{O}$ & 0.01 & $(0.01)$ & 0.22 & $(0.22)$ & 0.70 & $(0.74)$ & 0.51 & $(0.53)$ & 0.44 & $(0.45)$ & 0.08 & $(0.08)$ & 3.17 & $(3.25)$ & 2.71 & $(2.84)$ \\
\hline $\mathrm{K}_{2} \mathrm{O}$ & 0.05 & $(0.05)$ & 0.55 & $(0.57)$ & 0.05 & $(0.05)$ & 0.09 & $(0.09)$ & 0.37 & $(0.37)$ & 0.19 & $(0.20)$ & 0.09 & $(0.09)$ & 0.35 & $(0.36)$ \\
\hline $\mathrm{TiO}_{2}$ & 0.40 & $(0.43)$ & 0.55 & $(0.57)$ & 0.63 & $(0.66)$ & 0.87 & $(0.90)$ & 0.93 & $(0.95)$ & 0.52 & $(0.55)$ & 0.85 & $(0.87)$ & 1.60 & $(1,67)$ \\
\hline $\mathrm{P}_{2} \mathrm{O}_{5}$ & 0.03 & $(0.03)$ & 0.10 & $(0.10)$ & 0.10 & $(0.10)$ & 0.10 & $(0.10)$ & 0.10 & $(0.10)$ & 0.08 & $(0.08)$ & 0.10 & $(0.10)$ & 0.22 & $(0.23)$ \\
\hline $\mathrm{CO}_{2}{ }^{\circ}$ & - & & 0.05 & & 0,05 & & 0.05 & & 0.05 & & - & & 0.05 & - & - & - \\
\hline P.F. & 8.50 & & 3.77 & & 5.96 & & 4.19 & & 2.30 & & 4.30 & & 2.60 & - & 2.80 & - \\
\hline TOTAL & 99.89 & & 99.86 & & 100.31 & & 00.22 & & 100.12 & & 98.27 & & 100.01 & & 98.18 & \\
\hline & & & & & & & C & P. & & & & & & & & \\
\hline menita & 0.76 & $(0.84)$ & 0.91 & $(0.95)$ & 1.06 & $(1.19)$ & 1.52 & $(1.59)$ & 1.67 & $(1$ & 0.91 & $(0$ & 1.67 & $(1.72)$ & 3.04 & $(3,2$ \\
\hline rtoclásio & 0.00 & $(0.00)$ & 2.78 & (2.92) & 0.00 & $(0.00)$ & 0.00 & $(0.00)$ & 2.22 & $(2.15)$ & 1.10 & (1.16) & 0.00 & $(0.00)$ & 1.66 & $(1.74)$ \\
\hline Albita & 0.00 & $(0.00)$ & 1.57 & (1.64) & 5.76 & $(6.47)$ & 4.19 & $(4.40)$ & 3.66 & $(3.55)$ & 0.52 & $(0.55)$ & 26.72 & $(27.54)$ & 22.53 & $(24.01)$ \\
\hline Anortita & 7.50 & $(8.30)$ & 23.35 & $(24.52)$ & 4.72 & $(5.30)$ & 13.06 & (13.76) & 10.00 & $(9.70)$ & 24.18 & $(25.67)$ & 22.24 & $(22.92)$ & 32.52 & $(34.66)$ \\
\hline Corindon & 0.00 & $(0.00)$ & 0.00 & $(0.00)$ & 0.00 & $(0.00)$ & 0.00 & $(0.00)$ & 0.00 & $(0.00)$ & 0.00 & $(0.00)$ & 0.00 & $(0.00)$ & 0.00 & $(0.00)$ \\
\hline Magnetita & 10.67 & (11.43) & 1.16 & (1.21) & 0.00 & $(0.00)$ & 5.80 & $(6.10)$ & 4.87 & $(4.72)$ & 6.49 & $(6.89)$ & 5.56 & $(5.73)$ & 6.26 & $(6.67)$ \\
\hline Hematita & 0.00 & $(0.00)$ & 0.00 & $(0.00)$ & 0.00 & $(0.00)$ & 0.00 & $(0.00)$ & 0.00 & $(0.00)$ & 0.00 & $(0.00)$ & 0.00 & $(0.00)$ & 0.00 & $(0.00)$ \\
\hline Wolastonita & 3.49 & $(3.85)$ & 8.81 & $(9.95)$ & 12.64 & $(14.20)$ & 16.00 & $(16.82)$ & 20.18 & (19.59) & 10.32 & $(10.95)$ & 6.61 & $(6.81)$ & 7.42 & $(7.91)$ \\
\hline Enstatita & 2.90 & (3.21) & 6.10 & $(6.40)$ & 9.40 & $(10.56)$ & 11.20 & (11.77) & 14.40 & (13.98) & 7.90 & $(8.38)$ & 4.50 & $(4,63)$ & 4.10 & $(4.37)$ \\
\hline Ferrossilita & 0.13 & $(0.14)$ & 1.98 & $(2.07)$ & 1.98 & $(2.22)$ & 3.43 & $(3.60)$ & 3.06 & (3.84) & 1.32 & $(1.40)$ & 1.58 & $(1.62)$ & 3.03 & $(3.23)$ \\
\hline Hiperst. $(\mathrm{Mg})$ & 63.30 & $(70.09)$ & 34.20 & $(35.92)$ & 11.30 & $(12.69)$ & 20.40 & $(21.45)$ & 31.60 & $(30.67)$ & 34.70 & $(36.84)$ & 11.60 & $(11.95)$ & 13.40 & $(3.62)$ \\
\hline Hiperst. (Fe) & 0.13 & $(0.14)$ & 11.74 & $(12.23)$ & 2.24 & $(2.51)$ & 6.33 & $(6.65)$ & 8.84 & (8.58) & 5.94 & $(6.30)$ & 4.22 & $(4.35)$ & 2.64 & $(2.81)$ \\
\hline Forsterita & 1.40 & $(1.55)$ & 1.89 & $(1.98)$ & 32.90 & $(36.96)$ & 9.66 & $(10.15)$ & 0.00 & $(0.00)$ & 0.77 & $(0.81)$ & 8.82 & $(9.09)$ & 0.00 & $(0.00)$ \\
\hline Fayalita & 0.00 & $(0.00)$ & 0.71 & $(0.74)$ & 7.54 & $(8.47)$ & 3.46 & (3.63) & 0.00 & & 0.00 & $(0.00)$ & 3.46 & (3.56) & 0.00 & $(0.00)$ \\
\hline Quartzo & 0.00 & $(0.00)$ & 0.00 & $(0.00)$ & 0.00 & $(0.00)$ & 0.00 & $(0.00)$ & 1.62 & $(1.57)$ & 0.00 & $(0.00)$ & 0.00 & $(0.00)$ & 7.20 & $(7.67)$ \\
\hline
\end{tabular}

(1) - Clorita-tremolita-xisto (Unidade Morro do Niquel)

(2) - Epidoto-clorita-tremolita xisto (Unidade Morro do Niquel)

(3) - Clorita-tremolita-xisto (Unidade Morro do Níquel)

(4) - Tremolita-actinolita xisto (Unidade Morro do Níquel)

( ) - Valores (recalculados para $100 \%$ )

DEFINIÇÃO DO GRUPO DE DIFERENCIAÇÃO A série estudada, enquadra-se predominantemente no domínio correspondente às rochas toleíticas, transicionando para as seqüências basálticas ricas em alumina, evidenciadas pelo diagrama $\mathrm{SiO}_{2} / \mathrm{Na}_{2} \mathrm{O}+\mathrm{K}_{2} \mathrm{O}$ de Kuno (in Hess \& Poldervaart, 1968) (Fig. 2). Foram plotados no diagrama análises das lavas básicas e ultrabásicas. Locamos também lavas de composição
(5) - Serpentina-tremolita xisto (Unidade Morro do Níquel)

(6) - Clorita-tremolita xisto (Unidade Morro do Niquel)

(7) - Epidoto-tremolita-clorita xisto (Unidade Córrego do Salvador)

(8) - Epidoto-clorita-actinolita xisto (Unid. Córrego do Salvador)

Análises Geoquimicas por Espectrografia ótica Absorção Atômica e Fluorescência de Raios X Laboratório Geoquímico GEOLAB

ultrabásica de Alpinópolis (Biondi et al, 1977, inédito) que estão no mesmo contexto geológico da sequiência basal do Morro do Ferro (Fig. 2).

TENDÊNCIAS DA UIFERENCIAÇÃO Para isso, utilizou-se o indice de solidificação (IS) de Kuno (1968, op. cit), que constitui um bom índice de fracionamento magmático para rochas ricas em minerais 


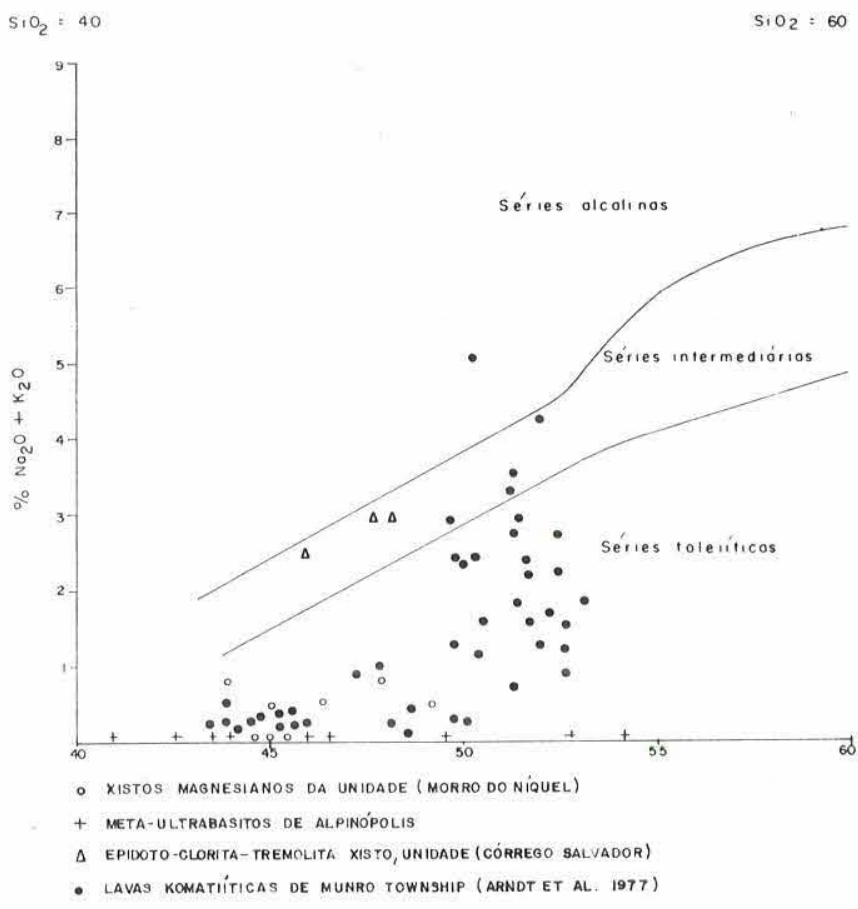

Figura 2 - Diagrama sílica/alcalinos com os campos das séries toleíticas, transicionais e alcalinas. Rochas da sequiência Morro do Ferro, comparada com as de Munro. mod. Arndt et al. (1977) e Alpinópolis (Biondi et al. 1977 Inédito)

máficos. Os baixos valores de IS no presente estudo, corresponderiam aos líquidos mais diferenciados. $\mathrm{Na}$ seqüência Morro do Ferro, tal comportamento pode ser constatado pelos gráficos da Fig. 3.
As porcentagens de $\mathrm{MgO}$ decrescem regularmente em direção aos termos mais diferenciados da série, caracterizando o processo de diferenciação controlado, sobretudo pelo fracionamento da olivina. Nos termos básicos, o comportamento do $\mathrm{MgO}$ indicaria uma maior participação na cristalização do piroxênio e uma diminuição no conteúdo de olivina. A variação do IS, situa-se entre 25 e 78 , para basaltos e lavas ultrabásicas, respectivamente.

Em relação aos teores de $\mathrm{Na}_{2} \mathrm{O}, \mathrm{K}_{2} \mathrm{O}$ e $\mathrm{Al}_{2} \mathrm{O}_{3}$, a série é caracterizada pelo enriquecimento destes óxidos, indicando uma participação mais abundante de feldspatos, que são derivados do fracionamento dos líquidos residuais da cristalização de olivina e piroxênio. Embora os teores de $\mathrm{K}_{2} \mathrm{O}$ sejam crescentes, são valores extremamente baixos.

O comportamento do titânio é marcado pela cristalização, principalmente de ilmenita e talvez de piroxênio. Na paragênese metamórfica atual, acha-se expresso como titanita. A diferenciação e enriquecimento nos termos mais básicos da série é bem evidente.

A distribuição de $\mathrm{FeO}, \mathrm{MnO}, \mathrm{Fe}_{2} \mathrm{O}_{3}$, apresenta um crescimento rumo aos termos mais diferenciados, possuindo um ponto de inflexão não muito evidente. A distribuição do cálcio não se mostra adequada para interpretações. Quando comparamos as curvas obtidas com as linhas clássicas de diferenciação, observamos inúmeras variações e dispersão de alguns pontos nos gráficos das rochas arqueanas. Como conclusão, consideramos tais resultados bastante precários, sugerindo inclusive que não se utilize tais métodos em suites de greenstone belt, sobretudo aqueles que mostram metamorfismo mais enérgico.

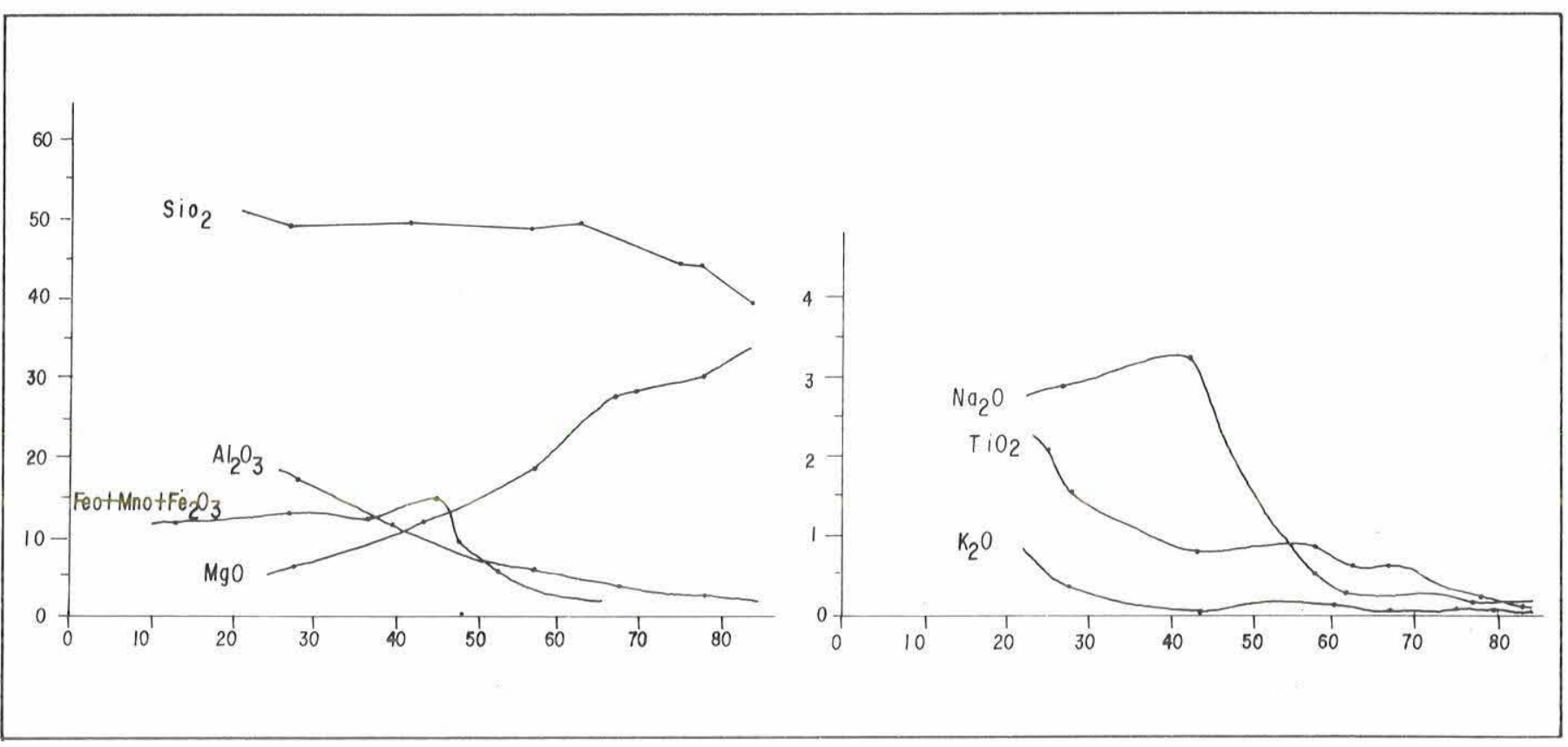

Figura 3 - Repartição dos óxidos na série Morro do Ferro. Prováveis Trends (I. S. índice de Kuno in Hess e Poldervoart, 1968) 


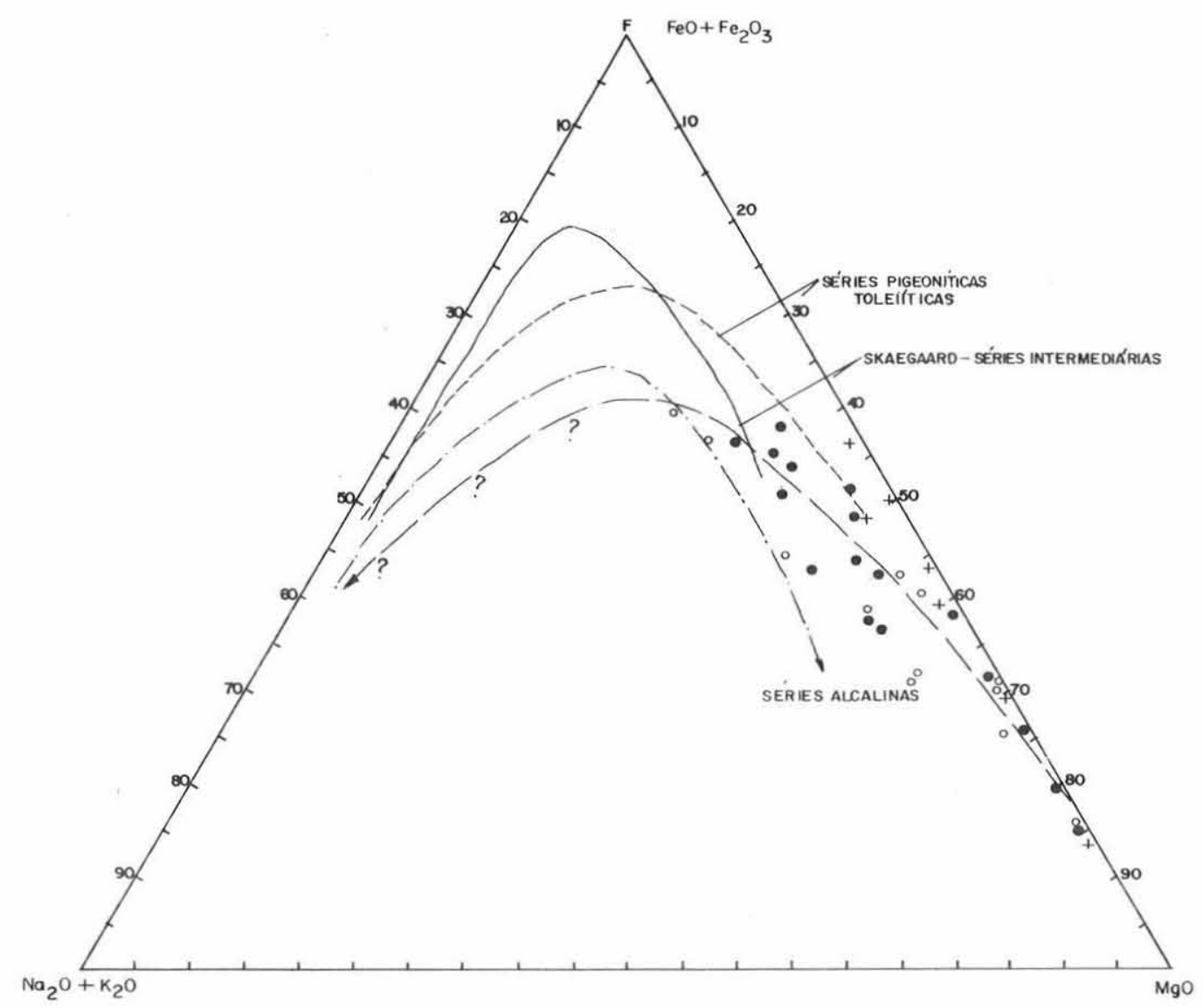

Figura 4 - Apresenta as linhas de diferenciação clássicas e comparação com as lavas arqueano. Há uma contínua evolução dos peridotitos, piroxenitos e basaltos

DIAGRAMA AFM Neste diagrama (Fig. 4), as rochas da seqüência evidenciaram um trend de diferenciação não muito evidente, evoluindo dos termos toleíticos, ricos em $\mathrm{FeO}$ e $\mathrm{MgO}$, para porções transicionais dos toleitos e as séries calco-alcalinas. Além disto, pode-se concluir a existência de um aumento progressivo de óxido de ferro e álcalis, com diminuição nos teores de $\mathrm{MgO}$. Tal tendência, acha-se refletida pela fixação do $\mathrm{Mg}$, Fe e $\mathrm{Ca}$ no piroxênio, olivina e magnetita, cristalizados nos estágios iniciais da diferenciação. O progressivo enriquecimento em álcalis permitiu a cristalização do feldspato, como mostra a migração dos pontos analisados em direção ao pólo $\mathrm{Na}_{2} \mathrm{O}+\mathrm{K}_{2} \mathrm{O}$. Os teores $\mathrm{Na}_{2} \mathrm{O}, \mathrm{TiO}_{2}, \mathrm{MgO}$ e $\mathrm{Al}_{2} \mathrm{O}_{3}$ são os que mais nitidamente separam os termos básicos dos ultrabásicos. As rochas de Munro, com exceção de algumas alteradas (ricas em álcalis), mostram o mesmo comportamento.

COMPARAÇÃO COM AS SEQÜÊNCIAS ARQUEANAS A constatação de que as lavas arqueanas mereciam ser quimicamente individualizadas como um novo grupo magmático, surgiu com os trabalhos de Viljoen e Viljoen (1969). Caracterizam tais rochas como komatiites, dotando-lhes das seguintes características químicas: $\mathrm{CaO} / \mathrm{Al}_{2} \mathrm{O}_{3}<1, \mathrm{MgO}>9 \%$ e $\mathrm{K}_{2} \mathrm{O}<0,9 \%$. Brooks e Hart (1974) propõem uma redefinição para o termo, uma vez que os simples parâmetros químicos são insuficientes para diferenciar peridotitos komatiiticos de qualquer outra classe de rocha, com quantidade significantes de clinopiroxênio ou anfibólio cálcico. Os parâmetros químicos utilizados por estes autores são $\mathrm{MgO}>9 \%, \mathrm{CaO} /$ $\mathrm{Al}_{2} \mathrm{O}_{3}<1, \mathrm{~K}_{2} \mathrm{O}<0,9 \%, \mathrm{TiO}_{2}<0,9 \%$. Arndt et al (1977) apresentam, como critérios de distinção do caráter komatítico, a ocorrência de lavas não cumuladas de composição ultrabásica portadoras de texturas spinifex; a baixa relação $\mathrm{Fe} / \mathrm{Mg}$ quando comparada com $\mathrm{Al}_{2} \mathrm{O}_{3}$; baixo $\mathrm{TiO}_{2} / \mathrm{SiO}_{2}$; e alto $\mathrm{MgO}, \mathrm{NiO}$ e $\mathrm{Cr}_{2} \mathrm{O}_{3}$.

A seqüência de xistos magnesianos da unidade Morro do Níquel, por possuir texturas spinifex e alta relação $\mathrm{FeO}^{*} / \mathrm{FeO}^{*}+\mathrm{MgO}$ e baixo $\mathrm{TiO}_{2} / \mathrm{SiO}_{2}$, corresponde perfeitamente aos flows ultrabásicos descri- 


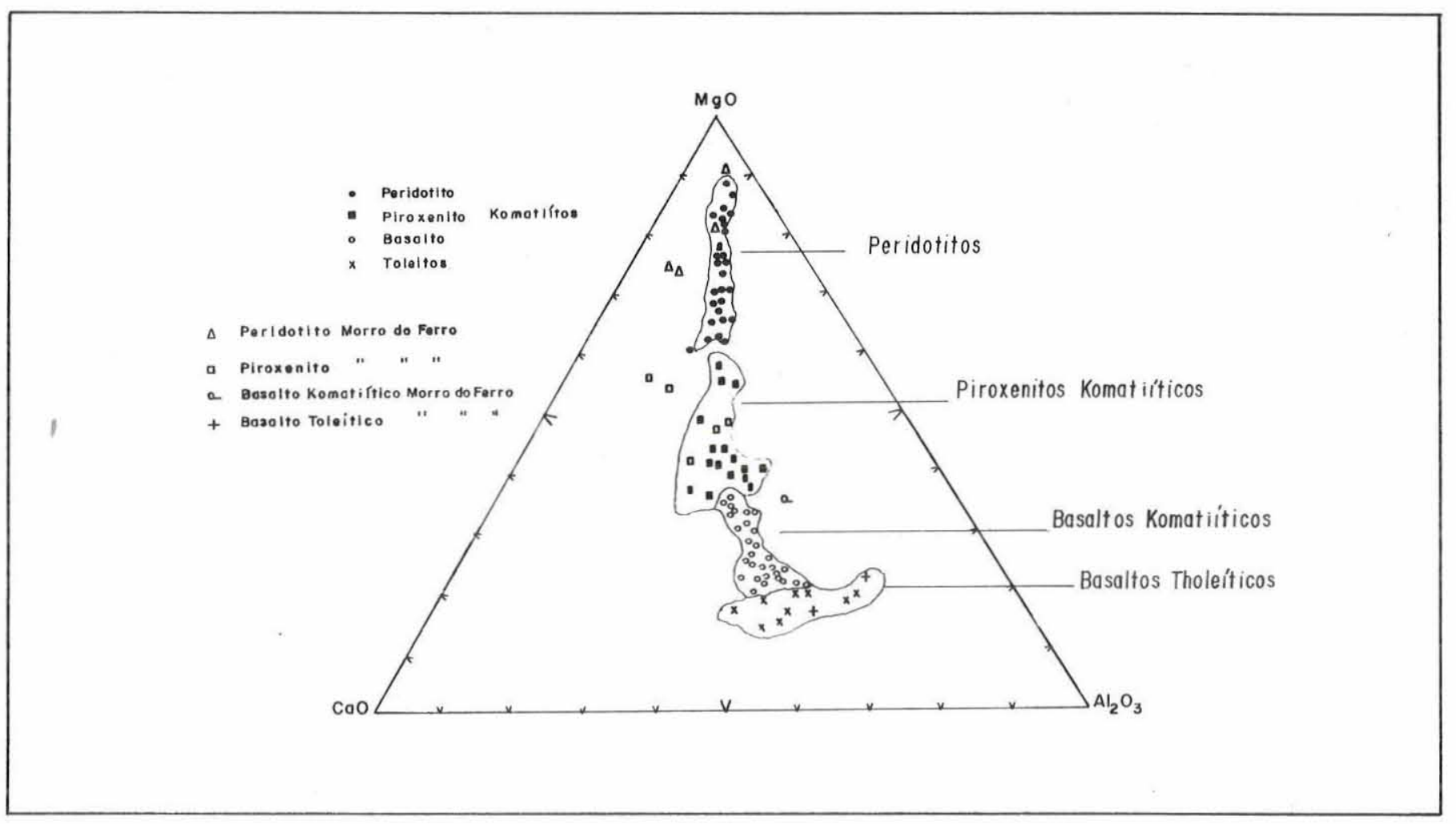

Figura 5-Diagrama das lavas Toleiticas e Komatíticas de Munro Township, comparadas com lavas da seqüência Morro do Ferro. Notar o trend contínuo: Peridotitos $\rightarrow$ Piroxenitos $\rightarrow$ Basaltos (Toléticos e Komatiíticos) modelo de Arndt et al. (1977)

tos nas sequiências vulcano-sedimentares arqueanas que serviram de padrões na definição da série komatítica. Ėm razão disto, é apresentado um conjunto de gráficos comparativos, com suites vulcânicas de outras regiões. Duas principais conclusões emergem da comparação dos diagramas químicos de suites komatíticas: a) os xistos magnesianos correspondem a derrames peridotíticos e piroxeníticos de filiação komatiítica; b) as lavas máficas, representadas por epidoto-tremolita-clorita xisto do Córrego Salvador, possuem quimismo toleítico e komatíítico. Outro aspecto importante a ser ressaltado, é que o estudo do quimismo das rochas evidenciou claramente a consanguineidade entre as porções ultrabásicas e básicas, uma vez que não há descontinuidade composicional entre os grupos litológicos analisados.

$\mathrm{O}$ diagrama $\mathrm{CaO}-\mathrm{MgO}-\mathrm{Al}_{2} \mathrm{O}_{3}$ (Fig. 5), evidencia que o trend é essencialmente caracterizado por um acréscimo de $\mathrm{MgO}$ numa razão mais ou menos constante de $\mathrm{CaO} / \mathrm{Al}_{2} \mathrm{O}_{3}$, refletindo a importância do fracionamento da olivina. Sugere, ainda, que os piroxenitos e basaltos resultam desde fracionamento, o qual é acompanhado por uma maior participação do clinopiroxênio e plagioclásio. Embora os valores da Sequiência Morro do Ferro estejam mais dispersos, o processo parece ser o mesmo que o estabelecido em Munro por Arndt et al (1977).
A Fig. 6 apresenta diagrama triangular ACM, onde estão locados os valores de rochas ultramáficas de algumas sequiências arqueanas (Nesbitt, 1971). A principal conclusão, embora estas rochas se apresentem serpentinizadas, é de que o trend de diferenciação se distancia linearmente do pólo $\mathrm{MgO}$, refletindo progressiva participação da cristalização do clinopiroxênio e subtração de olivina no curso da diferenciação.

$\mathrm{O}$ diagrama $\mathrm{Al}_{2} \mathrm{O}_{3}-\mathrm{FeO}^{*} /\left(\mathrm{FeO}^{*}+\mathrm{MgO}\right)$ da Fig. 7, compara os komatítos e toleitos de Munro com os da sequiência estudada. Os komatiítos possuem relação $\mathrm{FeO}^{*} /\left(\mathrm{FeO}^{*}+\mathrm{MgO}\right)$ mais baixa do que os toleitos de conteúdos similares de $\mathrm{Al}_{2} \mathrm{O}_{3}$. Os valores obtidos para as rochas estudadas, distribuem-se em vários campos, em razão da dispersão na coordenada $\mathrm{FeO} /(\mathrm{FeO}+\mathrm{MgO})$, que deve refletir a atuação do metamorfismo sobre tais rochas.

De todos os diagramas, talvez o representado na Fig. 8, seja o mais significativo, visto que a imobilidade do titânio durante os processos metamórficos permite considerar seus valores como representativos das rochas originais. Os teores de $\mathrm{TiO}_{2}$ são sempre maiores para os toleitos, quando comparados com os komatítos. As análises das porções ultramáficas, projetam-se no campo dos komatiítos. As rochas básicas variam desde komatiíto até toleíto. 


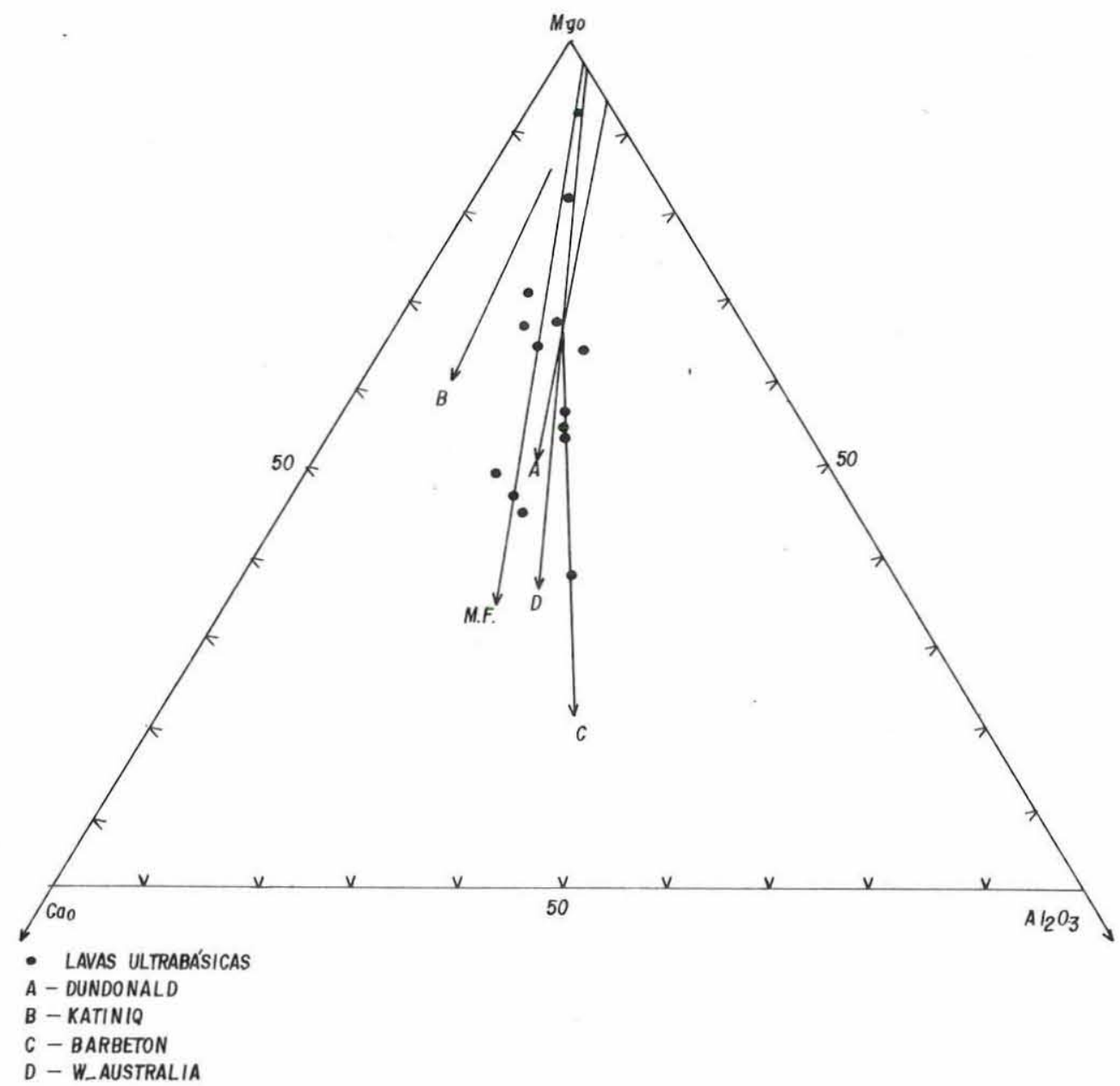

Figura 6-Diagramas mostrando os trends de fracionamento das rochas ultramáficas de diversas áreas arqueanos, comparadas com os xistos magnesianos da unidade Morro do Níquel modificado de Nesbitt (1971)

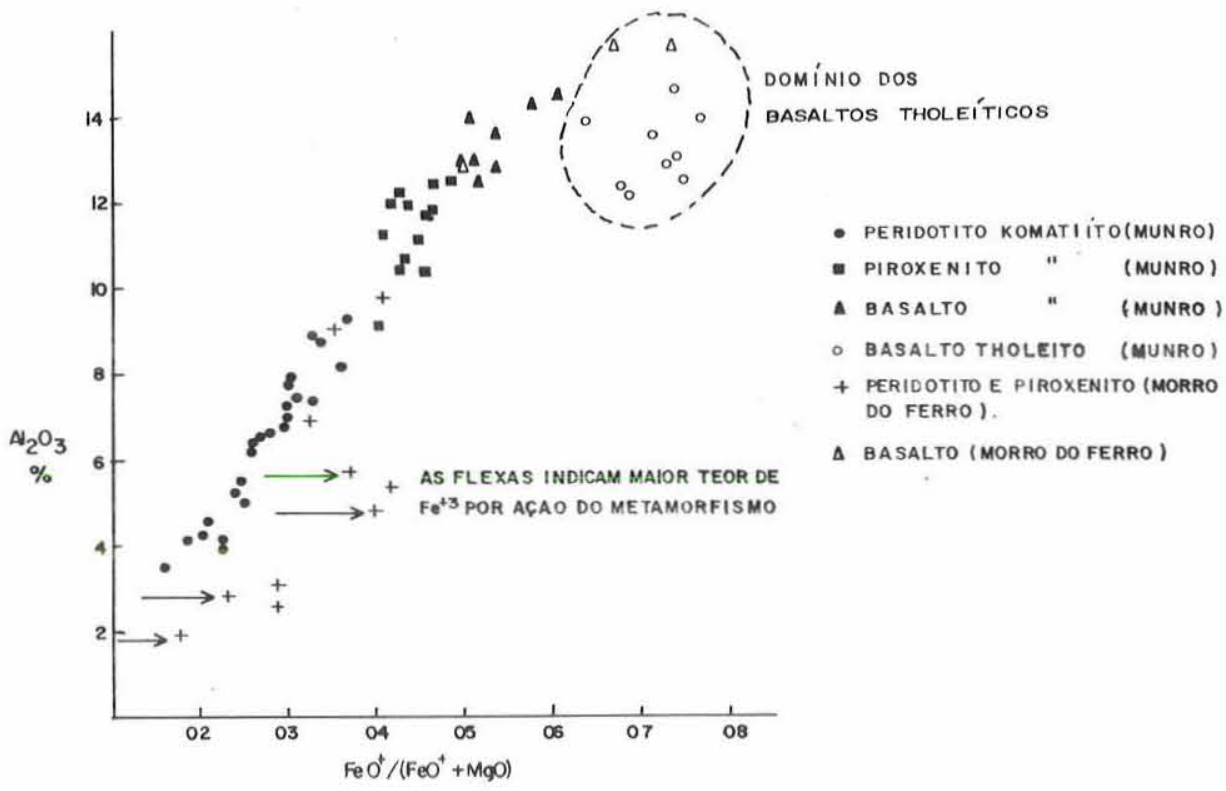

Figura $7-\mathrm{Al}_{2} \mathrm{O}_{3}$ vs. $\mathrm{FeO}^{+} /\left(\mathrm{FeO}^{+}+\mathrm{MgO}\right)$ mostrando a composição dos Komatiítos e toleítos de Munro e da seqüência Morro do Ferro. Mod. Arndt et al., (1977) 


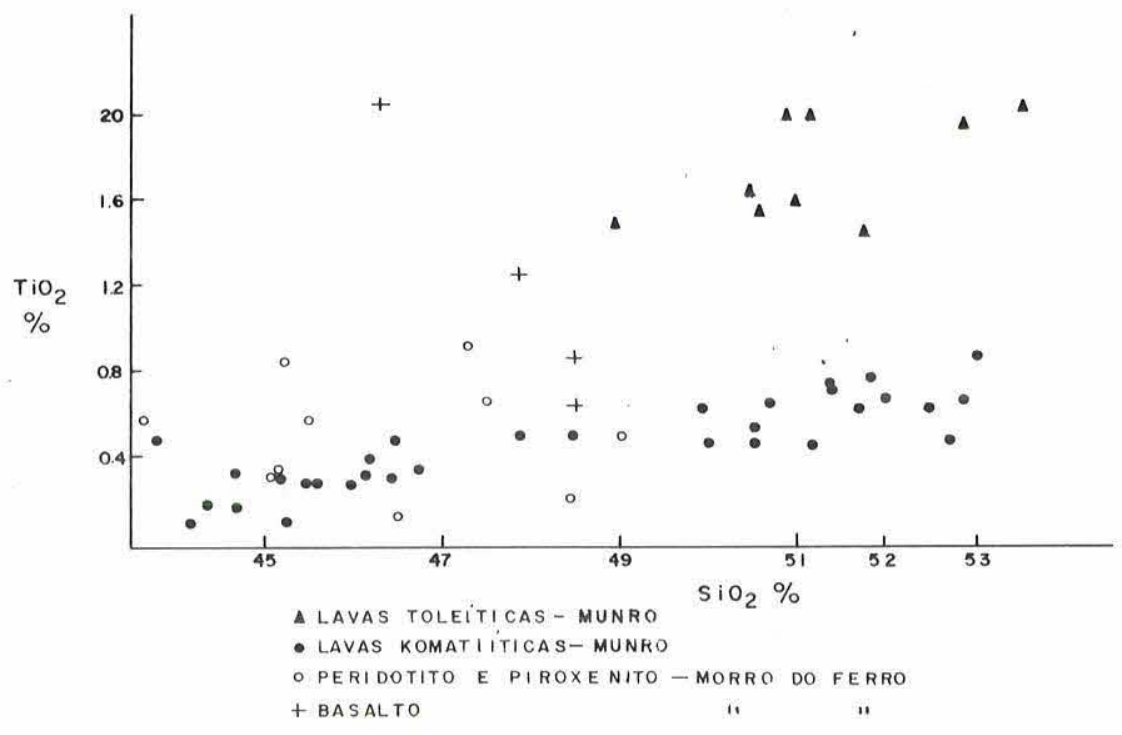

Figura $8-\mathrm{TiO}_{2}$ vs. $\mathrm{SiO}_{2}$ contraste de composição das lavas Komotiíticas e Toleíticas de Munro com basaltos, peridotitos e piroxenitos do Morro do Ferro. Mod. Arndt et al., (1977)

CONCLUSÓES O vulcanismo do cinturão apresenta da base para o topo, um trend de diferenciação interrompido pela deposição do mais espesso horizonte sedimentar.

A base é formada por corridas de lavas de composição ultrabásica e estratos químicos silicosos, depositados em períodos de quiescência vulcânica. Os derrames ultrabásicos, (peridotitos e piroxenitos), que constituem a Unidade Morro do Níquel, possuem texturas spinifex e quimismo komatítico.

Manifestações de vulcanismo básico, acha-se registrado na unidade intermediária, onde se verifíca recorrência do vulcanismo ultrabásico em escala res- trita. Estes basaltos possuem filiação komatítica: $\mathrm{MgO}=11,81 ; \quad \mathrm{CaO} / \mathrm{Al}_{2} \mathrm{O}_{3}=0,57 ; \quad \mathrm{K}_{2} \mathrm{O}<0,09 ;$ $\mathrm{TiO}_{2}=0,85$ e toleítica $\mathrm{MgO}=5,2 ; \mathrm{Ca} / \mathrm{Al}_{2} \mathrm{O}_{3}=$ $=0,95 ; \mathrm{TiO}_{2}=1,6$.

O fracionamento magmático evidenciado pela sequiência, demonstra a importância da cristalização precoce de olivina, seguida do clinopiroxênio e enriquecimento progressivo em álcalis, e conseqüente cristalização de feldspatos.

Agradecimentos Os autores agradecem a Metais de Minas Gerais S/A pelo apoio durante os trabalhos de campo e realização das análises.

\section{BIBLIOGRAFIA}

ARNDT, N. T.; NALDRETT, A. J. e PYKE, D. R. - 1977 - Komatiitic and Iron-rich Tholeiitic lavas of Munro Township, Northeast Ontario. - Journal of Petrology 18 (2): pp. 319-369.

BIONDI, J. C.; SCHRÁNCK, A.; PINHEIRO, J. C. F. - 1978 - Basitos e ultrabasitos do Espinhaço meridional e região sul de Minas - Relatório Interno da METAMIG S/A. (inédito).

BROOKS, C. e HART, S. R. - 1974 - On the significance of komatiite, Geology, 2 pp. 107-110.

HESS, H. H. e POLDERVAART, A. - 1968 - The Poldervaart treatise on rocks of basaltic Composition. - John Wiley e Sons, 2, pp. 623-688.

NESBITT, R. W. - 1971 - Skeletal crystal forms in the ultramafic rocks of the Yilgarn Block, Western Australia: Evidence for and archean ultramafic liquid. J. E. (ed.). Geol. Soc. Aust. Spec. Publ. n. ${ }^{\circ}$ 3, pp. 331-347.

PYKE, D. R.; NALDRETT, A. J. e ECKSTRAND, A. R. - 1973 - Archean ultramafic flows in Munro Township, Ontario. Can. Miner. 12, pp. 509-519.

SCHMIDT, E. e FLEISCHER, R. - 1978 - Estilo estrutural do Precambriano no sudeste de Minas Gerais. Anais do XXX Congresso Brasileiro de Geologia. 1, pp. 431-433.

TEIXEIRA, N. A. e DANNI, J. C. M. - 1979-Geologia da raiz de um Greenstone belt na porção sudoeste do Craton São Francisco (no prelo).

VILJOEN, M. J. e VILJOEN, R. P. -1969 - Evidence for the existence of a mobile extrusive peridotitic magma from the komatiitic formation of the Onverwacht group. Geol. Soc. Spec. Publ. 2, Upper Mantle Project, pp. 87-112. 